\title{
Base of the Fifth Metatarsal Fractures, an unusual presentation.
}

\author{
Maj AL SMITH \\ FRCS, RAMC \\ Specialist Registrar, Orthopaedics
}

\author{
Lt Col F KHAN \\ FRCS, RAMC \\ Consultant Orthopaedic Surgeon
}

\section{Miss A SOTT \\ FRCS \\ Senior Orthopaedic SHO}

Department of Orthopaedic Surgery, MDHU Frimley Park Hospital, Portsmouth Rd, Frimley, Surrey GU16 5UJ.

SUMMARY: We present a case of bilateral synchronous base of fifth metatarsal fractures in an otherwise fit lady.

\section{Case Report}

A healthy 41 year old lady wearing a pair of well known Swedish clogs stumbled whilst walking briskly. She suffered an inversion injury to the left ankle and in trying to regain her balance inverted the right ankle. She sustained bilateral fractures through the base of both fifth metatarsals (Fig 1).

She was treated conservatively with analgesia,

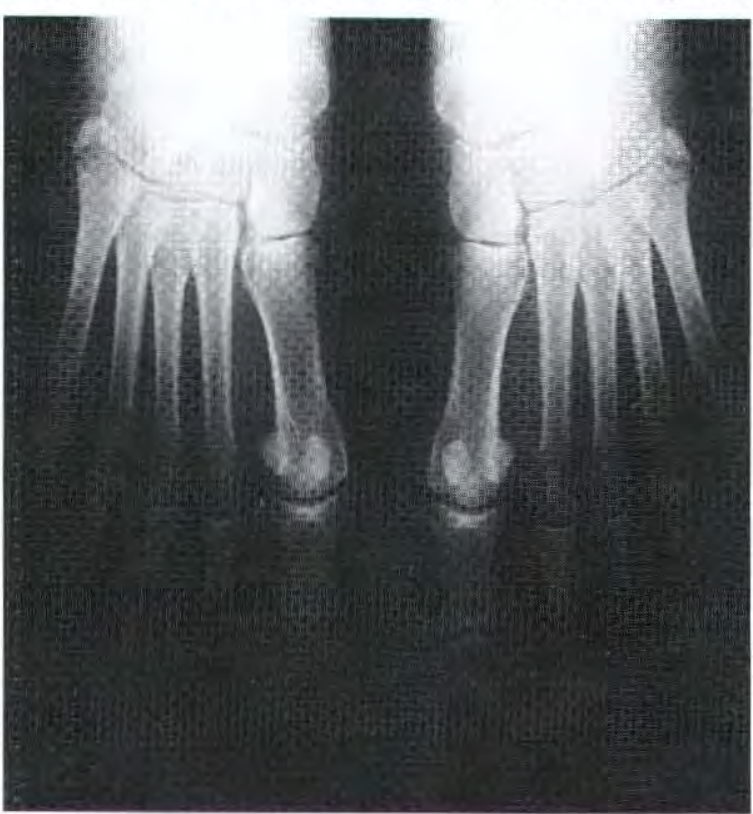

Fig 1. elasticated tubular bandages and two walking sticks. $\mathrm{Si} \frac{\mathrm{T}}{\mathbb{Q}} \overrightarrow{\mathrm{C}}$ weeks after her injury she had progressed to clinica and radiological union, with a return to full norma صِ activities.

\section{Discussion}

Fractures of this area are commonly referred to 'Jones' fractures after the original description of th injury sustained by Sir Robert Jones while dancing. He described a fracture approximately three quarters of an inch from the fifth metatarsal base' occurring as he (sic) 'trod on the outerside of my foot, my heel at the moment being off the ground.' (1). He concluded this fracture occurred by an indirect mechanism. This is generally thought to be as a result of an avulsion of bone secondary to Peroneus Brevis contracting, trying to prevent further foot inversion. However Richli and Rosenthal (2) in an anatomical study have shown the cause of this fracture to be avulsion by the lateral cord of the Plantar Aponeurosis. This inserts into the very tip of the fifth metatarsal; the Peroneus Brevis inserting slightly more distally.

Fractures of the fifth metatarsal all tend to be grouped under the eponym "Jones fracture". This is not strictly 8 correct as two distinct fracture patterns occur in this region .

1. Avulsion fracture of a variably sized piece of the tuberosity (not to be confused with Os peroneum or the much rarer sesamoid of Peroneus brevis, Os vesalianum. One should also remember the apophysis in this area fuses to the shaft by 16 years of age (3). 
2. Transverse fracture of the proximal metatarsal diaphysis within $1.5 \mathrm{~cm}$ of the tuberosity.

Avulsion fractures are almost always extra articular. These represent the true "Jones fracture". Torg (4) has further subdivided these into acute fractures, delayed unions and non unions; which forms a useful basis for management.

The acute fracture with minimal displacement is the commonest form of Jones fracture and is usually treated symptomatically using either a below knee walking cast or elasticated tubular bandage for 2 to 3 weeks. Operative intervention has been advocated in the primary treatment of these injuries $(5,6)$ claiming a more rapid return to full activities. However, this has been challenged by Arangio (7), who found no difference in recovery time between groups managed operatively or conservatively.

It is our practice to treat Jones fractures conservatively, initially with either elasticated tubular bandage or below knee walking cast as analgesia requirements dictate. This unusual case of bilateral synchronous fractures treated with minimal conservative therapy would appear to support this management pathway.

\section{REFERENCES}

1. JONES R. Fracture of the base of the fifth metatarsalo bone by indirect violence. Ann Surg 1902; 6970 क्ष़ 7000 .

2. Richli W R, ROSENTHAL DI. Avulsion fracture ot the fifth metatarsal: Experimental study ot pathomechanics. AJR 1984; 143: 889-891.

3. DAMERON TB, JR. Fractures and anatomica

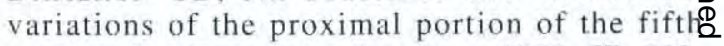
metatarsal. J Bone Joint Surg (Am) 1975; 57: 788요 792.

4. TORG JS, et al. Fractures of the base of the fifth metatarsal distal to the tuberosity. J Bone Joint Surg (Am) 1984; 66(2): 209-214.

5. Minbredo N, Shelbourne KD, Van Meter CD RETTLIG AC. Outpatient percutaneous screw fixatior? of the acute Jones fracture. Am J Sports Med 1993 21(5): 702-3.

6. O'Shea MK, Spack W, Sant 'Anna S, Johnson CO Clinical perspective of the treatment of the fifthmetatarsal fractures. J Am Podiatr Med Assoc 1995 